\title{
An evaluation of common breast cancer gene mutations in a population of Ashkenazi Jews
}

\author{
F Lalloo, S Cochrane, B Bulman, J Varley, R Elles, A Howell, D G R Evans
}

Family History Clinic, Department of Epidemiology, Christie NHS Trust, Kinnaird Road, Withington, Manchester M20 4QL, UK

F Lalloo

A Howell

D G R Evans

Department of Molecular Genetics, St Mary's Hospital for Women and Children, Hathersage Road, Manchester M13 0JH, UK

$S$ Cochrane

R Elles

Department of Cancer Genetics, Paterson Institute for Cancer Research, Christie NHS Trust, Wilmslow Road, Withington, Manchester M20 4BX, UK

B Bulman

J Varley

Correspondence to: Dr Evans.

Received 14 January 1997 Revised version accepted for publication 31 July 1997

\begin{abstract}
Objectives-In view of the recent reports of recurrent mutations in BRCA1 and BRCA2 in the Ashkenazi Jewish population, we have undertaken to assess the frequency of these mutations in this population attending for genetic counselling and risk assessment of familial breast cancer.
\end{abstract}

Design-Mutation screening for the $185 d e l A G$ and the 5382ins $C$ mutations in BRCA1 and the 6174delT mutation in BRCA2 was performed on DNA samples from either subjects affected by breast or ovarian cancer or obligate gene carriers. The likelihood of the cancers being hereditary in each family was calculated.

Subjects-Blood samples were obtained from 26 affected subjects or obligate gene carriers from 23 Ashkenazi Jewish families, all with a history of either early onset breast or ovarian cancers, or multiple cases of breast or ovarian cancer.

Results-Twelve mutations have been identified in the 23 families (52\%) of which eight $(67 \%)$ were the $185 \mathrm{del} A \mathrm{G}$ mutation, three $(25 \%)$ were the $6174 d e l T$ mutation, and one $(8 \%)$ was the 5382 ins $C$ mutation. While the majority of these mutations were identified in families with a greater than $50 \%$ probability of being hereditary under the CASH segregation model, three mutations were identified in families with a $35 \%$ or less probability.

Conclusions-Genetic screening of the recurrent mutations in Ashkenazi Jewish families will lead to the availability of predictive testing in a reasonably large proportion, even if the family history of breast/ovarian cancer is not particularly strong. In our view it is possible to reassure high risk unaffected members of these families, if the screening is negative for these mutations, even if a sample from an affected member of the family is unavailable for previous screening.

(f Med Genet 1998;35:10-12)

Keywords: Ashkenazi Jews; BRCA1/2 mutations

Breast cancer is the most common cancer in women. It has been estimated that $5 \%^{1}$ of breast cancer is inherited, with a number of highly penetrant autosomal dominant genes responsible for the majority of these cases. In 1990, BRCA1 was localised to chromosome $17^{2}$ and cloned in $1994 .^{3} \mathrm{~A}$ second gene, BRCA2, was localised in $1994^{4}$ and cloned in 1995.
Studies have shown that mutations in either BRCA1 or BRCA2 confer a lifetime risk of female breast cancer of $85 \%,{ }^{6}$ with BRCA1 also conferring a lifetime risk of ovarian cancer between 30 and $60 \%$. There is also an increased incidence of both bowel and prostate cancer associated with mutations in BRCA1. ${ }^{7}$ BRCA2 confers a higher risk of male breast cancer than BRCA1, but a lower risk of ovarian cancer. It also appears to be associated with an increased lifetime risk of bowel, prostate, and pancreatic cancer. $^{8}$

The mutation spectrum is large, with alterations occurring throughout the whole of both genes. ${ }^{90}$ However, there appear to be specific mutations in both BRCA1 and BRCA2 that have a high frequency within the Ashkenazi Jewish population. ${ }^{11}{ }^{12}$ This is the result of a founder effect. The 185delAG mutation in BRCA1 is thought to account for $16 \%$ of breast cancers and $39 \%$ of ovarian cancers occurring under the age of 50 years in Ashkenazi women. ${ }^{11} \mathrm{~A}$ second mutation in BRCA1, 5382insC, also occurs with an increased frequency. ${ }^{11}$ The 6174 delT mutation in BRCA2 is believed to be responsible for $8 \%$ of the early onset breast cancers in this population. ${ }^{12}$

The aim of this study was to assess the frequency of these mutations among a group of Jewish families attending genetic clinics in the north west of England.

\section{Methods}

Twenty-three families attending genetic clinics in Manchester for counselling for either breast or ovarian cancer have been identified as being of Ashkenazi Jewish descent. These families were classified according to their family history (table 1). Families were also stratified using epidemiological data from Claus et al,${ }^{13}$ Eby et $a l,{ }^{14}$ and Ponder et $a l^{15}$ as to the likelihood of being hereditary. Families ranged from a single case of breast cancer to families containing four or more cases of breast or ovarian cancer, with the breast cancers diagnosed under the age of 60 years. Blood samples were obtained from 26 members of these families, all of whom were affected subjects or obligate carriers.

All samples were screened for $185 \mathrm{delAG}$ and 5382insC in BRCA1 and 6174delT in BRCA2. The 185delAG mutation was detected using the amplification refractory mutations system (ARMS). A forward primer for exon 2 (5' GAAGTTGTCATTTTAAACCTTT 3') and a mutation specific reverse primer ( 5 ' CTTACCAGATGGGACACTAA $\left.3^{\prime}\right)$ were coupled with primers which would always amplify exon 14 of BRCA1 (14FP 5' 
Table 1 The differing pattern of cancers within the population screened

\begin{tabular}{ll}
\hline Group & Family history of cancers \\
\hline Group 1 & Single breast cancer diagnosed under 40 years \\
Group 2 & $\begin{array}{l}\text { Single breast cancer diagnosed 40-60 years } \\
\text { Two or more breast cancers diagnosed under } 70 \text { years }\end{array}$ \\
Group 4 & $\begin{array}{l}\text { Ovarian cancer only (2 cases) diagnosed under the age of } 60 \\
\text { Group 5 }\end{array}$ \\
Breast/ovary families (2-3 cases diagnosed under the age of 60$)$ \\
Breast Cancer Linkage Consortium Criteria (4 or more cases of breast or ovarian \\
cancer with the breast cancers diagnosed under the age of 60$)$
\end{tabular}

CTAACCTGAATTATCACTATCA 3', 14RP 5' GTGTATAAATGCCTGTATGCA 3').

The 5382ins C mutation in BRCA1 and the $6174 d$ delT mutation in BRCA2 were detected by single stranded conformation polymorphism analysis combined with heteroduplex analysis (SSCP/HA).

Exon 20 of BRCA1 was amplified (BR20F: 5' ATATGACGTGTCTGCTCCAC 3', BR20Rin: 5' TGCAAAGGGGAGTGGAA TAC $3^{\prime}$ ) as was the appropriate section of exon 11 of BRCA2 (BR11F: 5' GTAGCACGCATTCACATAAGGTT 3', BR11R: 5' GTGAGCTGGTCTGAATGTTCGTCGT 3').

The PCR products were then denatured at $95^{\circ} \mathrm{C}$ for five minutes and immediately put on ice. The DNA fragments were subsequently electrophoresed on a $6 \%$ polyacrylamide gel and detected by silver staining, as described previously. ${ }^{16}$ The original mutations found were confirmed by automated fluorescent sequencing.

\section{Results}

The 185 delAG mutation was observed in eight families, the 6174delT mutation in three families, and the 5382ins $\mathrm{C}$ mutations was detected in one family. Results of the mutation screening are presented in table 2 .

In total, 13 hereditary cases would have been expected based on epidemiological data and 12 were identified as being the result of the BRCA1/2 recurrent mutations. The five families fulfilling the Breast Cancer Linkage Consortium criteria had a mutation identified.

\section{Discussion \\ Previous studies ${ }^{11}$ have suggested that 185 delAG may account for up to $39 \%$ of early onset ovarian cancer and $16 \%$ of early onset breast cancer. Our study supports the fact that this mutation is more common in those families with a history of early ovarian cancer and in families where breast cancer has been diagnosed at a younger age. Eighty percent (five out of six) families with ovarian cancer had a 185delAG mutation, with one of these subjects being a male obligate carrier. Five of}

Table 2 Mutations detected among the varying family histories and the likelihood of the family histories having a genetic basis

\begin{tabular}{lllllll}
\hline Group & $\begin{array}{l}\text { No of } \\
\text { families }\end{array}$ & 185delAG & 6174delT & 5382insC & $\begin{array}{l}\text { Mutation } \\
\text { not detected }\end{array}$ & $\begin{array}{l}\text { No of families } \\
\text { expected to have } \\
\text { mutations in } \\
\text { predisposing genes }\end{array}$ \\
\hline 1 & 2 & 0 & 0 & 0 & 2 & 0.36 \\
2 & 2 & 0 & 1 & 0 & 1 & 0.24 \\
3 & 10 & 2 & 1 & 0 & 7 & 4.85 \\
4 & 2 & 2 & 0 & 0 & 0 & 1.26 \\
5 & 2 & 1 & 0 & 0 & 1 & 1.2 \\
6 & 5 & 3 & 1 & 1 & 0 & 5.0 \\
\hline
\end{tabular}

the eight 185delAG families had ovarian cancer which is broadly comparable to that found by Bergman et al. ${ }^{17}$ The $185 \mathrm{delAG}$ mutation was present in three of eight families with breast cancers diagnosed under the age of 40 years, but none of the families where breast cancer had been diagnosed at an older age. Again, although this figure is slightly higher than previously reported, it is within the $95 \%$ confidence limits of previous reports. ${ }^{18} 19$ The 185delAG mutation in BRCAl is also more prevalent among the families where one member has developed a second primary cancer.

It was surprising, however, that the BRCA2 mutation was found in families in whom the diagnoses of breast cancer were made at a later age. This is contrary to the results previously published showing a higher frequency of this mutation in early onset breast cancers. ${ }^{12}$ However, this may be in keeping with the suggestion that this mutation may have a lower penetrance than the BRCA1 mutations. ${ }^{12}$ The 5382insC mutation in BRCA1 was found in a family with a high probability of being genetic. Although this mutation has been found frequently in the general population, it does not appear to occur in the Ashkenazi population at the same frequency as the other two. ${ }^{9}$ This is in agreement with the results of our mutation screening.

In this study, $52 \%$ of the families studied had a mutation in either BRCA1 or BRCA2. Interestingly, some of the mutations were detected in families with minimal family histories; three mutations were found in families with a $35 \%$ or less probability of being hereditary under the CASH model. ${ }^{1}$ However, the majority of the 185delAG mutations were found in families with a high probability of having an inherited predisposition.

While this study shows that most of the mutations will be detected in families with a very strong family history (breast and ovarian cancers or multiple young onset breast cancers), screening for the 185delAG and 5382insC mutations in BRCA1 and the 6174delT mutation in BRCA2 in Ashkenazi families, even with a limited family history, is likely to lead to the possibility of predictive testing in a reasonably high proportion. Currently, presymptomatic testing is only undertaken if a mutation has already been detected in an affected member of the family. ${ }^{20}$ In the nonJewish population this often involves screening the entire coding sequence of BRCA1 and BRCA2. Even in families with four or more cases of breast or ovarian cancer, there is no certainty of identifying a mutation which will allow predictive testing. However, as the population frequency for $185 \mathrm{delAG}$ and $6174 \mathrm{delT}$ is $2.5 \%$, and that of the combined other mutations is probably only $0.2 \%$ (if similar to the non-Jewish population), screening of these mutations would be predicted to detect at least $90 \%$ of mutations in the Breast Cancer Linkage Consortium families.

The data take into account both high and low penetrance genes, and while these data show, for example, that $50 \%$ of families with two cases of breast cancer diagnosed under the 
age of 50 years have breast cancer because of a genetic predisposition, ${ }^{14}$ the Breast Cancer Linkage Consortium data suggest that only $10 \%$ are the result of mutations in BRCA1/2 (D Easton, personal communication). Both sets of data from the Breast Cancer Linkage Consortium and the CASH study ${ }^{121}$ are from largely non-Jewish populations.

The data from our study suggest that in the Ashkenazi Jewish population, mutations in BRCA1/2 account for the vast majority of inherited breast cancers. This is indicated by the fact that we have so far detected 12 of 13 expected (in a non-Jewish population) mutations using criteria for the likelihood of the cancers in these families being hereditary. This report therefore suggests that a simple screening test for three mutations may allow for a high degree of reassurance to unaffected at risk subjects in Jewish families where the mutation screenings are negative. Although more detailed work on Jewish populations is necessary, some reassurance may even be possible in situations where samples from a living affected relative are unavailable, particularly in families fulfilling Breast Cancer Linkage Consortium criteria.

1 Claus EB, Risch N, Thompson WD. Genetic analysis of breast cancer in the cancer and steroid hormone study. $\mathrm{Am}$ f Hum Genet 1991;48:232-42.

2 Hall JM, Lee MK, Newman B, et al. Linkage of early-onset familial cancer to chromosome 17q21. Science 1990;250: familial

3 Miki Y, Swensen J, Shattuck-Eidens D, et al. A strong candidate for the breast and ovarian cancer susceptibility gene, BRCA1. Science 1994;266:66-71.

4 Wooster R, Neuhausen SL, Mangion J, et al. Localization of a breast cancer susceptibility gene, BRCA2, to chromosome 13q12-13. Science 1994;265:2088-90.

5 Wooster R, Bignell G, Lancaster J, et al. Identification of the breast cancer gene BRCA2. Nature 1995;378:789-91.
6 Easton DF, Ford D, Bishop DT, and Breast Cancer Linkage Consortium. Breast and ovarian cancer incidence in BR

7 Ford D, Easton DF, Bishop DT, Narod SA, Goldgar DE. Risks of cancer in BRCA1-mutation carriers. Lancet 1994; 343:692-5.

8 Thorlacius S, Olafsdottir G, Tryggvadottir L, et al. A single BRCA2 mutation in male and female breast cancer families from Iceland with varied cancer phenotypes. Nat Genet 1996;13:117-19.

9 Shattuck-Eidens D, McClure M, Simard J, et al. A collaborative survey of 80 mutations in the BRCA1 breast and ovarian cancer susceptibility gene; implications for presymptomatic testing and screening. $\mathcal{F} A M A$ 1995;273:535sym.

10 Tavtigian SV, Simard J, Rommens J, et al. The complete BRCA2 gene and mutations on chromosome 13q-linked kindreds. Nat Genet 1996;12:333-7.

11 Struewing JP, Abeliovich D, Peretz T, et al. The carrier frequency of the BRCA1 185delAG mutation is approximately 1 percent in Ashkenazi Jewish individuals. Nat Genet 1995;11:198-200.

12 Neuhausen S, Gilewski T, Norton L, et al. Recurrent BRCA2 6174delT mutations in Ashkenazi Jewish women affected by breast cancer. Nat Genet 1996;13:126-8

13 Claus EB, Risch NJ, Thompson WD. Age at onset as an indicator of familial risk of breast cancer. Am $\mathcal{F}$ Epidemiol 1990;131:961-72.

14 Eby N, Chang-Claude J, Bishop DT. Familial risk and genetic susceptibility to breast cancer. Cancer Causes and Control 1994;5:458-70.

15 Ponder BAJ, Easton DF, Peto J. Risk of ovarian cancer associated with a family history: Preliminary report of the OPCS study. In: Sharp F, Mason WP, Leake RE, eds Ovarian cancer: biological and therapeutic challenges. Cambridge: Chapman and Hall, 1990:3-6.

16 Tassabehji M, Newton VE, Leverton $\mathrm{K}$, et al. PAX3 gene structure and mutations; close analogies between Waardenberg syndrome and the splotch mouse. Hum Mol Genet 1994;3:1069-74.

17 Bergman DB, Wagner-Costalas J, Schultz DC, Lynch HT, Daly $M$, Godwin AK. Two distinct origins of a common BRCA 1 mutation in breast-ovarian cancer families: genetic study of 15 185delAG-mutation kindreds. Am $\stackrel{\mathcal{J}}{ }$ Hum Genet 1996;58:1166-76.

18 Offitt K, Gilewski T, McGuire P, et al. Germline BRCA1 $185 \mathrm{del}$ AG mutations in Jewish women with breast cancer. Lancet 1996;347:1643-5.

19 Struewing JP, Brody LC, Erdos MR, et al. Detection of eight BRCA1 mutations in 10 breast-ovarian cancer families, including 1 family with male breast cancer. $\mathrm{Am} \mathcal{F} \mathrm{Hum}$ Genet 1995;57:1-7.

20 Eeles $R$. Testing for the breast cancer predisposition gene, BRCA1. BMF 1996;313:572-3.

21 Claus EB, Risch N, Thompson WD. Autosomal dominant inheritance of early-onset breast cancer; implications for risk prediction. Cancer 1994;73:643-51. 